\title{
Tiotropium reduces risk of exacerbations irrespective of previous use of inhaled anticholinergics in placebo-controlled clinical trials
}

\author{
This article was published in the following Dove Press journal: \\ International Journal of Chronic Obstructive Pulmonary Disease \\ 7 May 2011 \\ Number of times this article has been viewed
}

\author{
Christopher B Cooper' \\ Antonio Anzueto ${ }^{2}$ \\ Marc Decramer ${ }^{3}$ \\ Bartolome Celli ${ }^{4}$ \\ Donald P Tashkin' \\ Inge Leimer ${ }^{5}$ \\ Steven Kesten ${ }^{6}$ \\ 'David Geffen School of Medicine, \\ University of California, Los Angeles, \\ $\mathrm{CA} ;{ }^{2}$ University of Texas Health \\ Science Center, South Texas Veterans \\ Health Care System, San Antonio, \\ TX; ${ }^{3}$ University of Leuven, Leuven, \\ Belgium; ${ }^{4}$ Women's and Brigham \\ Hospital, Boston, MA; ${ }^{5}$ Boehringer \\ Ingelheim International GmbH, \\ Ingelheim, Germany; ${ }^{\circ}$ Uptake Medical \\ Corp, Tustin, CA, USA
}

\begin{abstract}
Background: Data have highlighted the potential bias introduced by withdrawal of inhaled corticosteroids at randomization in chronic obstructive pulmonary disease trials examining inhaled corticosteroids. Analyses were conducted to determine whether this was true of inhaled anticholinergic withdrawal in tiotropium trials.
\end{abstract}

Methods: A pooled analysis of randomized, double-blind, placebo-controlled, parallel-group tiotropium trials of at least six months' duration was performed. Trials had similar inclusion and exclusion criteria. Exacerbation definition was standardized. Patients were divided into two groups, ie, D (anticholinergics discontinued at randomization, previously prescribed) and ND (anticholinergics not discontinued, not previously prescribed).

Results: Demographics were balanced between the D $(n=5846)$ and ND $(n=6317)$ groups, except for higher cumulative smoking (56 pack-years versus 48 pack-years), lower forced expiratory volume in one second $\left(\mathrm{FEV}_{1}\right)$ /forced vital capacity (43\% versus $48 \%$ ), and lower baseline $\mathrm{FEV}_{1}$ (35.8\% predicted versus $42.4 \%$ predicted) in the $\mathrm{D}$ group. In both groups, tiotropium reduced the risk for an exacerbation (hazard ratio [HR] $=0.83, P<0.0001$ [D] versus $0.79, P<0.0001[\mathrm{ND}]$ ) and a hospitalized exacerbation $(\mathrm{HR}=0.85, P=0.0467$ versus $0.79, P=0.0094$ ). Tiotropium reduced the number of exacerbations per patient-year (rate ratio $[\mathrm{RR}]=0.82, P<0.0001[\mathrm{D}]$ versus $\mathrm{RR}=0.80, P<0.0001[\mathrm{ND}])$ and associated hospitalizations per patient-year $(\mathrm{RR}=0.88, P=0.015$ [D] versus $\mathrm{RR}=0.74, P<0.0001$ [ND]).

Conclusion: Tiotropium reduced exacerbations in patients who did and did not have anticholinergics discontinued upon randomization in clinical trials.

Keywords: chronic obstructive pulmonary disease, clinical trials, exacerbations, inhaled anticholinergics, tiotropium

\section{Introduction}

The randomized, controlled clinical trial is an attempt to minimize bias introduced by the knowledge of treatment allocation and, thereby, come to reliable conclusions regarding the hypothesis tested. Many interventional, randomized, controlled clinical trials need to assume that randomization distributes baseline characteristics equally, and that patients enter the clinical trial in a stable state. However, inclusion and exclusion criteria can lead to biases which are not necessarily anticipated. When the intervention examined is already used by any portion of the population, patients need to be withdrawn from the intervention. While this may be drug-specific, the withdrawal of previously prescribed medication is often based on the pharmacologic
Correspondence: Christopher B Cooper David Geffen School of Medicine, University of California, Los Angeles, 10833 Le Conte Avenue, 37-I3I CHS, Los Angeles, CA 90095-1690, USA

$\mathrm{Tel}+\mathrm{I} 3108254440$

Fax + I 31020682 II

Email ccooper@mednet.ucla.edu 
class or mechanism of action of the study drug. Most trials assume that patients are medically stable at randomization, but withdrawal of medication may worsen the underlying disease.

Three groups of investigators ${ }^{1-3}$ have highlighted issues introduced by withdrawal of inhaled corticosteroids at randomization into clinical trials examining inhaled corticosteroids in chronic obstructive pulmonary disease (COPD). Suissa et $\mathrm{al}^{1}$ concluded that the effects of withdrawal of medication cannot be assumed to be the same as addition of the medication. While the authors demonstrated this to be the case with inhaled corticosteroids, they considered whether withdrawal of other COPD medication, including inhaled anticholinergics, may lead to a similar phenomenon.

Our access to the tiotropium clinical trial database allowed us to undertake a thorough analysis of whether withdrawal of inhaled anticholinergics influenced the results observed with tiotropium on reducing COPD exacerbations. To our knowledge, this is the first analysis that has examined the issue of medication withdrawal at the onset of clinical trials of anticholinergic therapy.

\section{Methods}

\section{Study design}

A pooled analysis of 10 randomized, double-blind, placebocontrolled, parallel-group studies of at least six months' duration with tiotropium $18 \mu \mathrm{g}$ administered once daily via the HandiHaler ${ }^{\circledR}$ device (Boehringer Ingelheim $\mathrm{GmbH}$, Ingelheim, Germany) was performed (trial numbers $205.114 / 117,{ }^{4} 205.115 / 128,{ }^{5} 205.130,{ }^{6} 205.137,{ }^{6} 205.266,{ }^{7}$ $205.270,{ }^{8} 205.235$ [Understanding Potential Long-term Impacts on Function with Tiotropium (UPLIFT $\left.\left.{ }^{\circledR}\right)\right],{ }^{9}$ $205.214,{ }^{10} 205.256,{ }^{11} 205.259^{12}$ ), as shown in Figure 1. One study was longer than one year (UPLIFT, which included 5993 COPD patients followed over four years). ${ }^{9}$ All trials included evaluation of exacerbations and spirometry. Seven trials (trial numbers 205.114/117, 205.115/128, 205.130, 205.137, 205.235 [UPLIFT], 205.256, and 205.259) included measurement using the St George's Respiratory Questionnaire (SGRQ). ${ }^{13}$ All trial protocols were approved by independent ethics committees, and patients in all trials provided written informed consent. The trials were conducted in accordance with the Declaration of Helsinki.

\section{Study population}

All trials included in this pooled analysis had common entry criteria, ie, a clinical diagnosis of COPD, age $>40$ years,

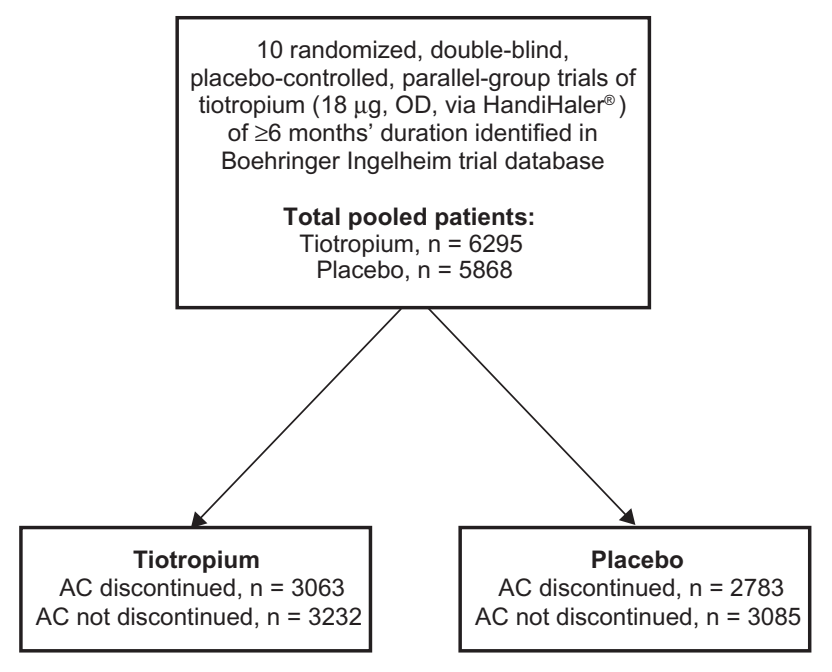

Figure I Study design overview. Patients from 10 pooled trials, receiving tiotropium or placebo, were analyzed according to whether they were receiving inhaled anticholinergics prior to participation in the trial, hence discontinued at trial start, or if they were not receiving inhaled anticholinergics at trial initiation, therefore did not discontinue (not discontinued).

Abbreviations: $A C$, anticholinergic; $O D$, once daily.

smoking history $\geq 10$ pack-years, postbronchodilator forced expiratory volume in one second $\left(\mathrm{FEV}_{1}\right) /$ forced vital capacity ratio $<0.7$, and $\mathrm{FEV}_{1}$ either $\leq 65 \%$ or $\leq 70 \%$ of predicted. Whilst the patients participating in these studies were classified as to the severity of their COPD on the basis of postbronchodilator $\mathrm{FEV}_{1}$ measurements, the data reported in this paper were prebronchodilator values.

Exclusion criteria included a history of asthma, the need for continuous supplemental oxygen, a COPD exacerbation within the previous six weeks, recent myocardial infarction or hospitalization for congestive heart failure, other unstable medical conditions that may preclude participation or interpretation of the results, and use of systemic corticosteroids in doses greater than the equivalent of prednisone $10 \mathrm{mg}$ daily. Responsiveness to bronchodilator therapy was not measured consistently between the clinical trials. Therefore, these measurements were not included in the data analysis. Consistent clinical criteria were applied to exclude patients with asthma. We believe that this is the most dependable method for excluding patients with asthma, given that it is now well known that bronchodilator responsiveness does not discriminate between asthma and COPD.

\section{COPD exacerbations}

All trials included data on COPD exacerbations. The following standardized definition was used to characterize COPD exacerbations in the current analysis: "An exacerbation is defined by two or more (increased or new-onset) 
respiratory symptoms such as cough, sputum, wheezing, dyspnea, or chest tightness, lasting at least three days, and requiring treatment with antibiotics and/or steroids, and/or hospitalization". ${ }^{14}$

Patients were grouped according to inhaled anticholinergic discontinuation, ie, D (anticholinergic prescribed prior to participation and discontinued at randomization) and ND (anticholinergic not prescribed prior to participation and therefore not discontinued).

\section{Data analysis}

Kaplan-Meier curves of the probability of no exacerbation and no hospitalization due to exacerbations were displayed. Cox regression was used to compute hazard ratios (HR) of tiotropium to placebo using trial as stratum.

The analysis of number of exacerbations and number of hospitalizations due to exacerbations was performed using Poisson regression, with correction for treatment exposure and overdispersion with terms for treatment subgroup and treatment by subgroup interaction. The effects of tiotropium or placebo on the SGRQ total score in trials where the SGRQ was measured was examined according to whether or not subjects discontinued anticholinergic therapy. These data are displayed as mean (standard error of the mean) values and have been compared with unpaired $t$-tests.

\section{Results}

\section{Demographics}

Of the 12,163 patients who were randomized into these clinical trials, 5846 were receiving inhaled anticholinergics that were discontinued at randomization (D group) and 6317 were not receiving inhaled anticholinergics at the time of randomization (ND group). The inhaled anticholinergic was ipratropium bromide in the vast majority of patients who were already receiving inhaled anticholinergics. At time of initiation of all of the aforementioned trials, tiotropium was not available in the respective countries where the studies were performed. Approval of tiotropium occurred in several of the trials during the recruitment phase. There were a few patients who did receive tiotropium prior to randomization (109 of 12,164 patients), with 49 being withdrawn from tiotropium. The baseline characteristics of these patients are shown in Table 1. For group $\mathrm{D}$, the mean age was 66.1 years compared with 64.5 years for the ND group. Gender distribution was similar across groups. Patients who had previously been prescribed anticholinergics had lower

Table I Baseline characteristics* of patients according to treatment allocation (tiotropium or placebo)

\begin{tabular}{|c|c|c|c|c|c|c|}
\hline & \multicolumn{3}{|c|}{ Discontinued } & \multicolumn{3}{|c|}{ Not discontinued } \\
\hline & Placebo & Tiotropium & Total & Placebo & Tiotropium & Total \\
\hline Number of patients (\%) & $2783(100.0)$ & $3063(100.0)$ & $5846(100.0)$ & $3085(100.0)$ & $3232(100.0)$ & $6317(100.0)$ \\
\hline Age, years & $66.1(8.6)$ & $66.1(8.4)$ & $66.1(8.5)$ & $64.6(9.0)$ & $64.4(8.8)$ & $4.5(8.9)$ \\
\hline \multicolumn{7}{|l|}{ Gender, n (\%) } \\
\hline Female & $577(20.7)$ & $623(20.3)$ & $1200(20.5)$ & $712(23.1)$ & $762(23.6)$ & $1474(23.3)$ \\
\hline Male & $2206(79.3)$ & $2440(79.7)$ & $4646(79.5)$ & $2373(76.9)$ & $2470(76.4)$ & $4843(76.7)$ \\
\hline \multicolumn{7}{|l|}{ Smoking history, n (\%) } \\
\hline Exsmoker & $1972(70.9)$ & $2176(71.0)$ & $4 \mid 48(7 \mid .0)$ & $2084(67.6)$ & $2193(67.9)$ & $4277(67.7)$ \\
\hline Never smoked & I $(0.0)$ & $0(0.0)$ & $\mathrm{I}(0.0)$ & $\mathrm{I}(0.0)$ & $0(0.0)$ & $\mathrm{I}(0.0)$ \\
\hline Smoker & $809(29.1)$ & $887(29.0)$ & $1696(29.0)$ & $1000(32.4)$ & $1038(32.1)$ & $2038(32.3)$ \\
\hline Missing & $I(0.0)$ & $0(0.0)$ & I $(0.0)$ & $0(0.0)$ & $I(0.0)$ & $\mathrm{I}(0.0)$ \\
\hline Smoking history, pack-years & $55.6(32.3)$ & $55.5(30.9)$ & $55.6(31.6)$ & $47.6(27.5)$ & $48.8(26.7)$ & $48.2(26.6)$ \\
\hline BMI & $26.3(5.5)$ & $26.4(5.5)$ & $26.4(5.5)$ & $26.2(5.3)$ & $26.3(5.3)$ & $26.2(5.3)$ \\
\hline $\mathrm{FEV}_{1}, \%$ predicted ${ }^{\dagger}$ & $36.0(12.4)$ & $35.7(12.3)$ & $35.8(12.4)$ & $42.0(12.6)$ & $42.7(12.8)$ & $42.3(12.7)$ \\
\hline $\mathrm{FEV}_{1} / \mathrm{FVC}^{\dagger}$ & $0.43(0.11)$ & $0.43(0.11)$ & $0.43(0.11)$ & $0.47(0.12)$ & $0.48(0.12)$ & $0.48(0.12)$ \\
\hline \multicolumn{7}{|l|}{ GOLD stage, n (\%) } \\
\hline 1 & $\mathrm{I}(0.0)$ & $0(0.0)$ & $\mathrm{I}(0.0)$ & $\mathrm{I}(0.0)$ & $7(0.2)$ & $8(0.1)$ \\
\hline II & $436(15.7)$ & $444(14.5)$ & $880(15.1)$ & $873(28.3)$ & $964(29.8)$ & $1837(29.1)$ \\
\hline III & $|35|(48.5)$ & $1509(49.3)$ & $2860(48.9)$ & $1614(52.3)$ & $1662(51.4)$ & $3276(51.9)$ \\
\hline IV & $966(34.7)$ & $1077(35.2)$ & $2043(34.9)$ & $554(18.0)$ & $548(17.0)$ & $1102(17.4)$ \\
\hline Missing & $29(1.0)$ & $33(1.1)$ & $62(1.1)$ & $43(1.4)$ & $5 \mathrm{I}(\mathrm{I} .6)$ & $94(1.5)$ \\
\hline Receiving systemic corticosteroids, n (\%) & $295(10.6)$ & $283(9.2)$ & $578(9.9)$ & $137(4.4)$ & 145 (4.5) & $282(4.5)$ \\
\hline
\end{tabular}

Notes: *Mean (SD) unless otherwise specified. No BMI data available for study 205.214 because weights were not collected; ${ }^{\dagger}$ prebronchodilator values. GOLD based on prebronchodilator values: Stage I = mild ( $F E V_{1} \geq 80 \%$ predicted); Stage II = moderate ( $F E V_{1}<80 \%$ to $\geq 50 \%$ predicted); Stage III $=$ severe (FEV $<50 \%$ to $\geq 30 \%$ predicted); Stage IV = very severe ( $\mathrm{FEV}_{1}<30 \%$ predicted). "Not discontinued" means either "not discontinued from anticholinergics" or "never took anticholinergics".

Abbreviations: BMI, body mass index; FEV , forced expiratory volume in I second; FVC, forced vital capacity; GOLD, Global Initiative for Chronic Obstructive Lung Disease; SD, standard deviation. 
lung function and longer smoking histories. Overall, within the D and ND groups, the treatment subgroups (tiotropium and placebo) were reasonably well balanced with respect to their baseline characteristics.

\section{Exacerbations}

There was a significantly reduced risk of an exacerbation in patients receiving tiotropium compared with those receiving placebo in the D group (HR [95\% confidence interval $(\mathrm{CI})]=0.83[0.77-0.90])$ and in the ND groups (HR $[95 \%$ $\mathrm{CI}]=0.79[0.73-0.85])$. Similar findings were observed for exacerbations leading to hospitalizations with an HR $(95 \%$ CI) of $0.85(0.73-1.00)$ in the D group and $0.79(0.65-0.94)$ in the ND group. Tiotropium delayed the time to first exacerbation and first hospitalized exacerbation in both the $\mathrm{D}$ and ND groups, as observed in the cumulative incidence displays (Figures 2 and 3).

The number of patients having at least one exacerbation and at least one exacerbation leading to hospitalization was reduced with tiotropium relative to placebo in both $\mathrm{D}$ and

A

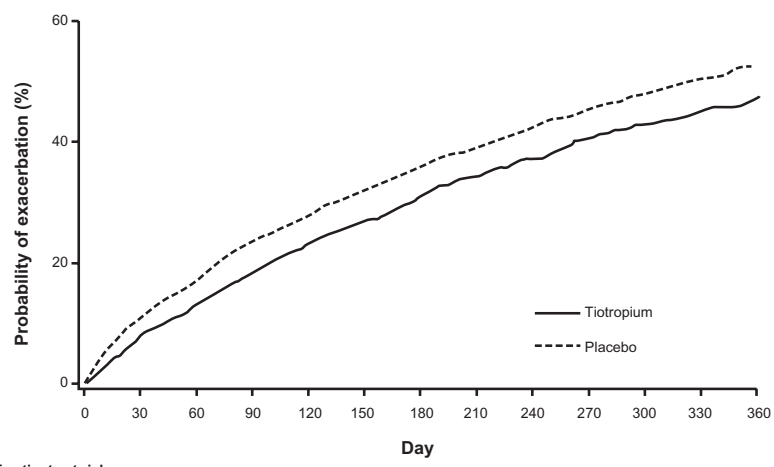

No. of patients at risk:

$\begin{array}{llllllllllllll}\text { Tiotropium } & 3063 & 2750 & 2565 & 2364 & 2200 & 2070 & 1740 & 1271 & 1192 & 1071 & 1010 & 930 & 658\end{array}$ $\begin{array}{llllllllllllll}\text { Placebo } & 2783 & 2329 & 2124 & 1915 & 1781 & 1661 & 1373 & 978 & 910 & 823 & 770 & 704 & 546\end{array}$

B

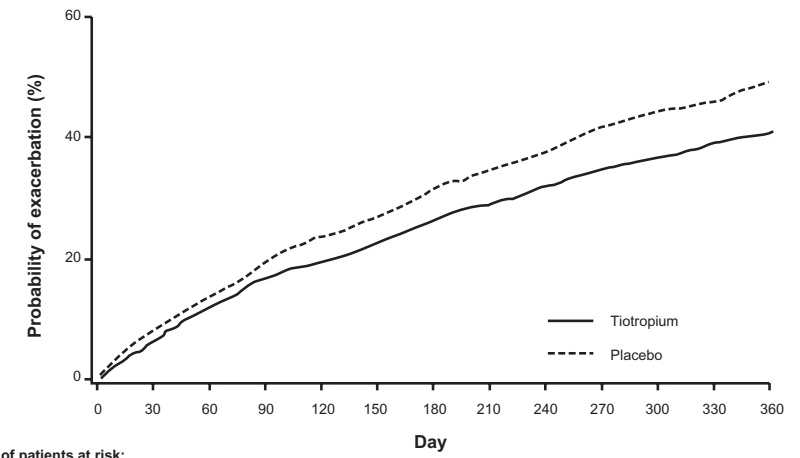
No. of patients at risk:

$\begin{array}{llllllllllllll}\text { Tiotropium } & 3232 & 2957 & 2733 & 2551 & 2438 & 2327 & 2021 & 1840 & 1754 & 1554 & 1443 & 1321 & 937\end{array}$ $\begin{array}{llllllllllllll}\text { Placebo } & 2085 & 2741 & 2527 & 2310 & 2168 & 2044 & 1741 & 1539 & 1455 & 1278 & 1154 & 1061 & 799\end{array}$

Figure 2 Cumulative incidence estimate (Kaplan-Meier) of the probability of a COPD exacerbation. Tiotropium delayed time to first exacerbation $\mathbf{A}$ ) in patients who discontinued inhaled anticholinergics at randomization; and $\mathbf{B}$ ) in patients who were not prescribed inhaled anticholinergics prior to randomization (ie, no discontinuation of inhaled anticholinergics).

Abbreviation: COPD, chronic obstructive pulmonary disease.

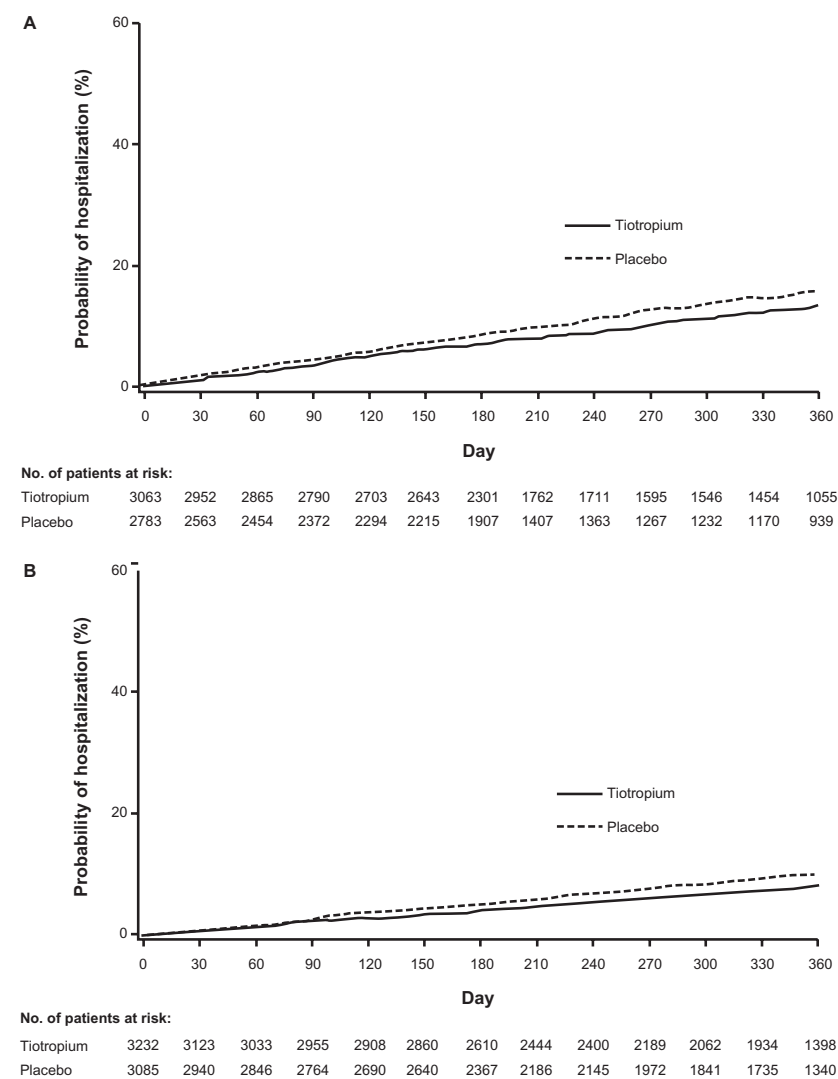

Figure 3 Cumulative incidence estimate (Kaplan-Meier) of the probability of a COPD exacerbation leading to a hospitalization. Tiotropium reduced the probability of experiencing an exacerbation $\mathbf{A}$ ) in patients who discontinued inhaled anticholinergics at randomization; and B) in patients who were not prescribed inhaled anticholinergics prior to randomization (ie, no discontinuation of inhaled anticholinergics).

Abbreviation: COPD, chronic obstructive pulmonary disease.

ND groups, as reflected by lower rate ratios (Tables 2 and 3). Furthermore, these effects were similar for patients in both $\mathrm{D}$ and ND groups.

\section{St. George's respiratory questionnaire}

For the D group, the mean (standard error) total SGRQ score at six months was improved with tiotropium (41.4 [0.31]) relative to those receiving placebo (44.7 [0.34], difference $=3.33[0.40], P<0.0001)$. For the ND group, the total scores were also improved with tiotropium versus placebo (40.3 compared with 43.1, difference $=2.78$, $P<0.0001)$.

\section{Discussion}

The pooled analysis of 10 randomized, double-blind, placebo-controlled clinical trials involving 12,163 patients with COPD demonstrates that tiotropium was effective in reducing exacerbations in patients who did and also those who did not have inhaled anticholinergics discontinued upon 
Table 2 Number of patients with at least one exacerbation by discontinuation of anticholinergics

\begin{tabular}{lllll}
\hline & $\begin{array}{l}\text { Placebo } \\
(\mathbf{n}=\mathbf{5 8 6 8})\end{array}$ & $\begin{array}{l}\text { Tiotropium } \\
(\mathbf{n}=\mathbf{6 2 9 5 )}\end{array}$ & $\mathbf{n}(\%)$ & $\begin{array}{l}\text { Odds ratio } \\
\text { (95\% confidence } \\
\text { interval) }\end{array}$ \\
\hline Discontinued & $1187(42.7)$ & $1221(39.9)$ & $0.88(0.80-0.93)$ & $P$ value \\
Not discontinued & $1294(41.9)$ & $1154(35.7)$ & $0.77(0.69-0.85)$ & 0.0223 \\
Difference & & & & $<0.0001$ \\
\hline
\end{tabular}

Notes: Results are based on a logistic regression model with terms for treatment, subgroup, trial and treatment *subgroup interaction. The denominator for the percentages is the number of patients in each combination of subgroup and treatment: discontinued, $\mathrm{n}$ (placebo) $=2783$, $\mathrm{n}$ (tiotropium) $=3063$; not discontinued $\mathrm{n}$ (placebo) $=3085$, $\mathrm{n}($ tiotropium $)=3232$.

randomization. In patients who discontinued anticholinergic therapy, there was a $17 \%$ risk reduction for an exacerbation when treated with tiotropium compared with placebo. In patients who did not discontinue anticholinergic therapy, the risk reduction was $21 \%$ with tiotropium compared with placebo. In a similar comparison, the risk for a hospitalized exacerbation was reduced by $15 \%$ and $21 \%$, respectively. The reduced risk was also associated with reduced rates of exacerbations and hospitalized exacerbations, regardless of previous anticholinergic use. Thus, withdrawal of inhaled anticholinergics upon entry into tiotropium trials did not appear to influence the effect of tiotropium on the clinically important patient outcome of exacerbations of COPD. In addition, in the seven trials where the SGRQ was measured, tiotropium significantly reduced the SGRQ total score in both groups of patients.

Exacerbations are a significant component of the clinical course in COPD. ${ }^{15,16}$ Furthermore, as COPD progresses, exacerbations become more frequent. ${ }^{16}$ Some investigators have suggested that more frequent exacerbations are associated with more rapid decline of $\mathrm{FEV}_{1} \cdot{ }^{17,18}$ Certainly, exacerbations have profound effects on quality of life. ${ }^{19}$ For example, SGRQ scores have been shown to be decreased (worsened) below baseline for up to six months following an exacerbation. ${ }^{20}$ Finally, exacerbations are associated with significant mortality. ${ }^{21}$ More widespread clinical use of tiotropium in COPD patients might predictably ameliorate the effects of recurrent exacerbations on the clinical course of the disease and impact the design of future clinical trials.
Recently, there have been increasing concerns about the effects of withdrawal of medications on the entry into clinical trials. van der Valk et $\mathrm{al}^{3}$ treated patients with inhaled fluticasone $1000 \mu \mathrm{g} /$ day for four months and then randomized the patients to continue receiving fluticasone or to switch to placebo. During the subsequent six months of follow-up, $47 \%$ of patients in the fluticasone group developed a COPD exacerbation compared with $57 \%$ in the placebo group. Significant differences were seen in the HR for first exacerbation, as well as differences in health-related quality of life as measured by the SGRQ, which favored those patients continuing on fluticasone. However, the question arises as to whether this is a safety concern due to sudden withdrawal of a high dose of systemically absorbed inhaled corticosteroids or if the observations are surrogate measures of efficacy.

Suissa et $\mathrm{al}^{1}$ described methodological issues in therapeutic trials of COPD, and drew attention to the problem of medication withdrawal using inhaled corticosteroids prior to randomization as an example. In the case of the Towards a Revolution in COPD Health (TORCH) study, this phenomenon led in effect to two comparisons, ie, withdrawal of inhaled corticosteroids compared with continuation of inhaled corticosteroids in patients previously taking these agents, and introduction of inhaled corticosteroids compared with placebo in patients not previously taking inhaled corticosteroids. Suissa et $\mathrm{al}^{1}$ also analyzed data from the Canadian Optimal Therapy of COPD Trial ${ }^{22}$ and found that the HR (inhaled corticosteroids relative to bronchodilators

Table 3 Number of patients with at least one hospitalization by discontinuation of anticholinergics

\begin{tabular}{|c|c|c|c|c|}
\hline & $\begin{array}{l}\text { Placebo } \\
(n=5868) \\
n(\%)\end{array}$ & $\begin{array}{l}\text { Tiotropium } \\
(n=6295) \\
n(\%)\end{array}$ & $\begin{array}{l}\text { Odds ratio } \\
\text { ( } 95 \% \text { confidence } \\
\text { interval) }\end{array}$ & $P$ value \\
\hline Discontinued & $315(11.3)$ & $320(10.4)$ & $0.92(0.78-1.09)$ & 0.3173 \\
\hline Not discontinued & $255(8.3)$ & $215(6.7)$ & $0.79(0.66-0.96)$ & 0.0160 \\
\hline Difference & & & & 0.2473 \\
\hline
\end{tabular}

Notes: Results are based on a logistic regression model with terms for treatment, subgroup, trial and treatment *subgroup interaction. The denominator for the percentages is the number of patients in each combination of subgroup and treatment: discontinued: $n$ (placebo) $=2783$, $n$ (tiotropium) $=3063$; not discontinued: $n$ (placebo) $=3085$, $\mathrm{n}($ tiotropium $)=3232$. 
only) for the first exacerbation among previous inhaled corticosteroids users was 0.71 (95\% CI 0.53-0.96), while among those not using inhaled corticosteroids prior to randomization, the $\mathrm{HR}$ (inhaled corticosteroids relative to bronchodilators only) was 1.11 (95\% CI 0.69-1.79). In addition, the ratio for exacerbations in patients prior to discontinuing inhaled corticosteroids was $0.78(95 \%$ CI 0.61-0.99) compared with 1.23 (95\% CI 0.78-1.95) thereafter. These concerns prompted a detailed retrospective analysis of data from TORCH. ${ }^{23}$ In this paper, Keene et al argued that a negative binomial model was the best approach to statistical analysis of exacerbation rates and that a similar reduction in exacerbations could be calculated regardless of whether or not subjects had discontinued inhaled corticosteroids at randomization.

Suissa et $\mathrm{al}^{1}$ suggested in their paper that withdrawal of inhaled anticholinergic therapy might cause similar problems to those they described related to withdrawal of inhaled corticosteroids. However, our results clearly refute that suggestion. Furthermore, we have demonstrated a similar reduction in the number of exacerbations per patient year in those who continued and those who discontinued inhaled anticholinergic therapy upon randomization into these tiotropium clinical trials. This significant benefit argues that the clinical trial results, in terms of the difference between tiotropium and placebo, favor a positive effect from tiotropium rather than a negative effect from inhaled anticholinergic withdrawal in the placebo group.

As well as demonstrating that tiotropium reduced exacerbations regardless of changes in prior therapy, we were also able to demonstrate that tiotropium, when compared with placebo, improved health-related quality of life (as measured by SGRQ), regardless of whether or not patients had been taking inhaled anticholinergic therapy prior to randomization. The improvement in SGRQ was statistically significant for both the D and ND groups, although numerically greater for those patients who discontinued previous anticholinergic therapy. Such improvements are a predictable complement to the effect on exacerbations.

We can speculate why withdrawal of inhaled anticholinergic therapy does not affect the outcome of placebo-controlled clinical trials of tiotropium, whereas withdrawal of inhaled corticosteroids seems to be problematic. The effect of ipratropium, which is the short-acting anticholinergic taken by many patients prior to entry into the tiotropium trials, is well understood to be restricted to antimuscarinic smooth muscle relaxation and presumably wears off relatively quickly, although there is some evidence that the effects of extended therapy with ipratropium persist longer than the conventional 6-8-hour duration of acute bronchodilation. ${ }^{24}$ Although considered a short-acting bronchodilator, ipratropium alone or in combination with albuterol has been shown to reduce exacerbations compared with albuterol alone. ${ }^{25}$ This observation suggests that one should consider whether a "rebound" effect (ie, an increase in exacerbation rate) might be a consequence of ipratropium withdrawal. In a study of nine subjects with mild asthma, Newcomb et $\mathrm{al}^{26}$ described a short-term increase in airway hyperresponsiveness to methacholine upon withdrawal of regular use of ipratropium, which could represent upregulation of muscarinic receptors on the surface of airway smooth muscle cells. However, these findings have not been replicated, and the current analysis demonstrates that a rebound worsening of COPD is unlikely to occur upon withdrawal of ipratropium. The corollary is not necessarily true for inhaled corticosteroids, because there are systemic effects of inhaled corticosteroids and both beneficial effects and adverse events are likely to occur over longer periods of time, which may also delay the onset of safety issues.

As with any meta-analysis, our study has certain limitations. ${ }^{27}$ We acknowledge that this is a retrospective analysis and includes trials of different size and duration. However, the strengths of the study are the prospective nature of the clinical trials selected for the pooled analysis and the consistency of their entry criteria. Furthermore, these studies were rigorously conducted, randomized, doubleblind, controlled clinical trials that provided large numbers of patients, all of whom were included in the analysis.

\section{Conclusion}

In summary, we have demonstrated that tiotropium reduced exacerbations and hospitalizations in a large number of COPD patients, regardless of whether or not they discontinued inhaled anticholinergic therapy prior to randomization into the placebo-controlled clinical trials. These findings strengthen the validity of conclusions previously reported from these clinical trials that treatment with tiotropium reduces exacerbations, and that the beneficial effect is equally observed whether or not patients had previously received inhaled anticholinergic therapy.

\section{Acknowledgment}

We wish to acknowledge the support of Dacheng Liu (Boehringer Ingelheim) for the statistical analysis. 


\section{Disclosure}

Preparation of this paper was funded jointly by Boehringer Ingelheim and Pfizer. The study design, collection, analysis, and interpretation of data were funded by Boehringer Ingelheim and Pfizer.

\section{References}

1. Suissa S, Ernst P, Vandemheen KL, Aaron SD. Methodological issues in therapeutic trials of COPD. Eur Respir J. 2008;31(5):927-933.

2. O'Brien A, Russo-Magno P, Karki A, et al. Effects of withdrawal of inhaled steroids in men with severe irreversible airflow obstruction. Am J Respir Crit Care Med. 2001;164(3):365-371.

3. van der Valk P, Monninkhof E, van der Palen J, Zielhuis G, van Herwaarden C. Effect of discontinuation of inhaled corticosteroids in patients with chronic obstructive pulmonary disease: The COPE study. Am J Respir Crit Care Med. 2002;166(10):1358-1363.

4. Casaburi R, Mahler DA, Jones PW, et al. A long-term evaluation of once-daily inhaled tiotropium in chronic obstructive pulmonary disease. Eur Respir J. 2002;19(2):217-224.

5. Calverley PM, Lee A, Towse L, van Noord J, Witek TJ, Kelsen S. Effect of tiotropium bromide on circadian variation in airflow limitation in chronic obstructive pulmonary disease. Thorax. 2003;58(10): $855-860$

6. Brusasco V, Hodder R, Miravitlles M, Korducki L, Towse L, Kesten S. Health outcomes following treatment for six months with once daily tiotropium compared with twice daily salmeterol in patients with COPD. Thorax. 2003;58(5):399-404.

7. Niewoehner DE, Rice K, Cote C, et al. Prevention of exacerbations of chronic obstructive pulmonary disease with tiotropium, a once-daily inhaled anticholinergic bronchodilator: A randomized trial. Ann Intern Med. 2005;143(5):317-326.

8. Powrie DJ, Wilkinson TM, Donaldson GC, et al. Effect of tiotropium on sputum and serum inflammatory markers and exacerbations in COPD. Eur Respir J. 2007;30(3):472-478.

9. Tashkin DP, Celli B, Senn S, et al. A 4-year trial of tiotropium in chronic obstructive pulmonary disease. $N$ Engl J Med. 2008;359(15): 1543-1554.

10. Dusser D, Bravo ML, Iacono P. The effect of tiotropium on exacerbations and airflow in patients with COPD. Eur Respir J. 2006;27(3): 547-555.

11. Tonnel AB, Perez T, Grosbois JM, Verkindre C, Bravo ML, Brun M. Effect of tiotropium on health-related quality of life as a primary efficacy endpoint in COPD. Int J Chron Obstruct Pulmon Dis. 2008;3(2): 301-310.

12. Chan CK, Maltais F, Sigouin C, Haddon JM, Ford GT. A randomized controlled trial to assess the efficacy of tiotropium in Canadian patients with chronic obstructive pulmonary disease. Can Respir J. 2007; 14(8):465-472.

13. Jones PW, Quirk FH, Baveystock CM, Littlejohns P. A self-complete measure of health status for chronic airflow limitation. The St George's Respiratory Questionnaire. Am Rev Respir Dis. 1992;145(6): 1321-1327.

International Journal of COPD

\section{Publish your work in this journal}

The International Journal of COPD is an international, peer-reviewed journal of therapeutics and pharmacology focusing on concise rapid reporting of clinical studies and reviews in COPD. Special focus is given to the pathophysiological processes underlying the disease, intervention programs, patient focused education, and self management protocols.
14. Celli BR, MacNee W. Standards for the diagnosis and treatment of patients with COPD: A summary of the ATS/ERS position paper. Eur Respir J. 2004;23(6):932-946.

15. Halpern MT, Stanford RH, Borker R. The burden of COPD in the USA: Results from the Confronting COPD survey. Respir Med. 2003; 97(Suppl C):S81-S89.

16. Global strategy for the diagnosis, management, and prevention of chronic obstructive pulmonary disease. NHLBI/WHO workshop summary. Updated 2007. Available at: http://www.goldcopd.com. Accessed March 18, 2011.

17. Donaldson GC, Seemungal TA, Bhowmik A, Wedzicha JA. Relationship between exacerbation frequency and lung function decline in chronic obstructive pulmonary disease. Thorax. 2002;57(10):847-852.

18. Anzueto A, Leimer I, Kesten S. Impact of frequency of COPD exacerbations on pulmonary function, health status and clinical outcomes. Int J Chron Obstruct Pulmon Dis. 2009;4:245-251.

19. Spencer S, Calverley PM, Burge PS, Jones PW. Impact of preventing exacerbations on deterioration of health status in COPD. Eur Respir J. 2004;23(5):698-702.

20. Seemungal TA, Donaldson GC, Bhowmik A, Jeffries DJ, Wedzicha JA. Time course and recovery of exacerbations in patients with chronic obstructive pulmonary disease. Am J Respir Crit Care Med. 2000; 161(5):1608-1613.

21. Connors AF Jr, Dawson NV, Thomas C, et al. Outcomes following acute exacerbation of severe chronic obstructive lung disease. The SUPPORT investigators (Study to Understand Prognoses and Preferences for Outcomes and Risks of Treatments). Am J Respir Crit Care Med. 1996;154(4 Pt 1):959-967.

22. Aaron SD, Vandemheen KL, Fergusson D, et al. Tiotropium in combination with placebo, salmeterol, or fluticasone-salmeterol for treatment of chronic obstructive pulmonary disease: A randomized trial. Ann Intern Med. 2007;146(8):545-555.

23. Keene ON, Vestbo J, Anderson JA, et al. Methods for therapeutic trials in COPD: Lessons from the TORCH trial. Eur Respir J. 2009;34(5): $1018-1023$.

24. Rennard SI, Serby CW, Ghafouri M, et al. Extended therapy with ipratropium is associated with improved lung function in patients with COPD. A retrospective analysis of data from seven clinical trials. Chest. 1996;110(1):62-70.

25. Friedman M, Serby CW, Menjoge SS, Wilson JD, Hilleman DE, Witek TJ Jr. Pharmacoeconomic evaluation of a combination of ipratropium plus albuterol compared with ipratropium alone and albuterol alone in COPD. Chest. 1999;115(3):635-641.

26. Newcomb R, Tashkin DP, Hui KK, Conolly ME, Lee E, Dauphinee B. Rebound hyperresponsiveness to muscarinic stimulation after chronic therapy with an inhaled muscarinic antagonist. Am Rev Respir Dis. 1985;132(1):12-15.

27. Pogue J, Yusuf S. Overcoming the limitations of current meta-analysis of randomised controlled trials. Lancet. 1998;351(9095):47-52.
This journal is indexed on PubMed Central, MedLine and CAS. The manuscript management system is completely online and includes a very quick and fair peer-review system, which is all easy to use. Visit http://www.dovepress.com/testimonials.php to read real quotes from published authors. 